\title{
Neuropharmacology and Management of Chemotherapy-Induced Nausea and Vomiting in Patients with Breast Cancer
}

\author{
Karin Jordan ${ }^{\mathrm{a}}$ Judith Schaffrath ${ }^{\mathrm{a}}$ Franziska Jahn ${ }^{\mathrm{a}}$ Carsten Mueller-Tidow ${ }^{\mathrm{a}}$ Berit Jordan ${ }^{\mathrm{b}}$ \\ ${ }^{a}$ Department of Hematology/Oncology, Martin Luther University Halle/Wittenberg, Germany \\ ${ }^{\mathrm{b}}$ Department of Neurology, Martin Luther University Halle/Wittenberg, Germany
}

\section{Keywords}

Chemotherapy-induced nausea and vomiting .

Antiemetic guidelines $\cdot 5-\mathrm{HT}_{3}$ receptor antagonists .

Neurokinin receptor antagonist

\section{Summary}

Advances in our understanding of the pathophysiology of chemotherapy-induced nausea and vomiting (CINV), the identification of patient risk factors, and the development of new antiemetics have led to significant improvements in CINV prevention. With the correct use of antiemetic drugs, CINV can be prevented in the majority of patients. Extensive clinical data have been considered in the development of antiemetic treatment recommendations by reliable institutions such as the Multinational Association of Supportive Care in Cancer, the European Society of Medical Oncology and the American Society for Clinical Oncology. These guidelines are intended to enable physicians to incorporate the latest clinical research into their daily practice, considering CINV prevention as part of an optimal patient-centered approach to cancer management. Yet despite the availability of these guidelines, there is emerging evidence that implementation of treatment recommendations is suboptimal. Recently, guideline committees gave special consideration to patient-related risk factors (young, females) contributing to the emetogenic potential for patients receiving anthracycline and cyclophosphamide-based chemotherapy. As women with breast cancer represent a particularly challenging population regarding emesis control, it is especially important that treatment recommendations are followed. This review focuses on the content of the current antiemetic guidelines, addressing the importance of how these are intended to be implemented in routine clinical practice.

\section{KARGER}

Fax +497614520714

Information@Karger.com

www.karger.com
(C) 2014 S. Karger GmbH, Freiburg

1661-3791/14/0094-0246\$39.50/0

Accessible online at:

www.karger.com/brc

\section{Introduction}

For patients receiving chemotherapy, if not prevented, nausea and vomiting can be a significant problem. Besides being among the most distressing side effects of chemotherapy, chemotherapy-induced nausea and vomiting (CINV) may interfere with patients' daily functioning and negatively affect their quality of life. It can also have detrimental clinical implications for patients, including non-compliance with or premature discontinuation of potentially curative cancer treatment, as well as impeding patients' willingness or ability to eat and/or drink, leading to nutritional deficits. Without appropriate antiemetic prophylaxis, up to $90 \%$ of all cancer patients receiving chemotherapy may experience nausea and/or vomiting. Therefore, complete prevention of these side effects has to be the goal of all antiemetic therapy.

Over the past 25 years, continuous research has led to steady improvements in the field of supportive care for cancer patients. With the introduction of the 5- $\mathrm{HT}_{3}$ receptor antagonists (5-HT 3 RAs) in the early 1990s and another class of antiemetics, the neurokinin-1 $\left(\mathrm{NK}_{1}\right)$ receptor antagonists 10 years ago, there have been significant improvements in the prevention and control of CINV. The first international Multinational Association of Supportive Care in Cancer (MASCC) antiemetic guidelines were published in 1998 and were immediately followed by the American Society of Clinical Oncology (ASCO) guidelines in 1999. Since that time these guidelines have been updated regularly as new data have emerged. [1,2].

During this same time period, significant advances and a paradigm shift have occurred in the treatment of breast cancer, with research evolving toward a more molecular targeted approach. Despite these advances, the majority of breast cancer patients continue to receive emetogenic cytotoxic chemotherapy regimens, sometimes combined with novel targeted 
Table 1. Emetogenic risk of selected intravenous and oral chemotherapeutic agents relevant in breast cancer treatment; adapted from $[1,2]$

\begin{tabular}{|c|c|}
\hline Risk & Chemotherapeutic agent \\
\hline \multicolumn{2}{|c|}{ High (emesis risk $>90 \%$ without antiemetics) } \\
\hline \multicolumn{2}{|r|}{ Carmustine, BCNU } \\
\hline \multicolumn{2}{|r|}{ Cisplatin } \\
\hline & Cyclophosphamide $\left(>1,500 \mathrm{mg} / \mathrm{m}^{2}\right)$ \\
\hline \multicolumn{2}{|c|}{ Moderate (emesis risk $30-90 \%$ without antiemetics) } \\
\hline \multicolumn{2}{|r|}{ Intravenous: } \\
\hline \multicolumn{2}{|r|}{ Carboplatin } \\
\hline \multicolumn{2}{|r|}{ Cyclophosphamide $\left(<1,500 \mathrm{mg} / \mathrm{m}^{2}\right)$} \\
\hline \multicolumn{2}{|r|}{ Doxorubicin* } \\
\hline \multicolumn{2}{|r|}{ Epirubicin* } \\
\hline \multicolumn{2}{|r|}{ Ifosfamide } \\
\hline \multicolumn{2}{|r|}{ Irinotecan } \\
\hline \multicolumn{2}{|r|}{ Oxaliplatin } \\
\hline \multicolumn{2}{|r|}{ Temozolomide } \\
\hline \multicolumn{2}{|r|}{ Oral: } \\
\hline \multicolumn{2}{|r|}{ Cyclophosphamide } \\
\hline \multicolumn{2}{|r|}{ Temozolomide } \\
\hline \multicolumn{2}{|c|}{$\begin{array}{l}\text { Vinorelbine } \\
\text { Low (emesis risk } 10-30 \% \text { without antiemetics) }\end{array}$} \\
\hline \multicolumn{2}{|r|}{ Intravenous: } \\
\hline \multicolumn{2}{|r|}{ Catumaxumab } \\
\hline \multicolumn{2}{|r|}{ Docetaxel } \\
\hline \multicolumn{2}{|r|}{ Doxorubicin liposomal } \\
\hline \multicolumn{2}{|r|}{ Etoposide } \\
\hline \multicolumn{2}{|r|}{ 5-Fluorouracil } \\
\hline \multicolumn{2}{|r|}{ Gemcitabine } \\
\hline \multicolumn{2}{|r|}{ Methotrexate $\left(>100 \mathrm{mg} / \mathrm{m}^{2}\right)$} \\
\hline \multicolumn{2}{|r|}{ Mitoxantron } \\
\hline \multicolumn{2}{|r|}{ Paclitaxel } \\
\hline & Topotecan \\
\hline & Trastuzumab \\
\hline & Oral: \\
\hline & Capecitabine \\
\hline & Everolimus \\
\hline Mini & $\begin{array}{l}\text { Lapatinib } \\
\text { (emesis risk }<10 \% \text { without antiemetics) }\end{array}$ \\
\hline & Bevacizumab \\
\hline & Hormones \\
\hline & Pertuzumab \\
\hline & Vincristine \\
\hline & Vinorelbine \\
\hline
\end{tabular}

*Emetogenicity of these anthracyclines is increased when combined with cyclophosphamide.

therapies. During the most recent review of the antiemetic guidelines, the committees gave special consideration to the patient-related risk factors that contribute to the emetogenic potential for breast cancer patients receiving the commonly used anthracycline and cyclophosphamide (AC)-based chemotherapy regimens. They acknowledged that this group is at higher risk for CINV than that expected with AC alone. It is, therefore, particularly important that efforts be made to fol- low the guideline recommendations for antiemetic prophylaxis in patients with breast cancer.

\section{Neuropharmacology of Emesis}

While the pathophysiology of CINV is not entirely understood, it is known to be multifactorial, involving multiple pathways, neurotransmitters and receptors. CINV is believed to occur largely via 2 pathways: (1) a peripheral pathway involving neurotransmitters activated as a result of gastrointestinal irritation or damage by chemotherapy, and (2) a central pathway involving activation of neurotransmitters in the chemoreceptor trigger zone (CTZ) directly through the blood or cerebrospinal fluid.

Following exposure to radiation or cytotoxic drugs, seroto$\operatorname{nin}(5-\mathrm{HT})$ is released from enterochromaffin cells in the small intestinal mucosa, which are adjacent to the vagal afferent neurons on which $5-\mathrm{HT}_{3}$ receptors are located. The released serotonin binds to the $5-\mathrm{HT}_{3}$ receptors, thereby activating vagal afferent neurons, which transmit impulses to the CTZ of the brain. At present, this vagal-dependent peripheral pathway is considered the primary mechanism by which chemotherapeutic agents initiate acute emesis. The central pathway is activated by substance $\mathrm{P}$, abundant in the CTZ in the area postrema at the bottom of the fourth ventricle. Substance $\mathrm{P}$ induces vomiting by binding to $\mathrm{NK}_{1}$ receptors, which are highly concentrated in the brain. In early studies it was shown that administration of substance $\mathrm{P}$ to dogs could induce emesis [3]. Multiple studies have suggested that substance $\mathrm{P}$ may be the most relevant neurotransmitter associated with delayed CINV [4].

While serotonin $/ 5-\mathrm{HT}_{3}$ receptors and substance $\mathrm{P} / \mathrm{NK}_{1}$ receptors play the predominant role in the emesis response, other neurotransmitters and receptors are also involved. These include dopamine $(\mathrm{D}) / \mathrm{D}_{2}$ and $\mathrm{D}_{3}$ receptors, cannabinoids $(\mathrm{CBs}) / \mathrm{CB}_{1}$ receptors, histamine $(\mathrm{H}) / \mathrm{H}_{1}$ receptors, and acetylcholine/muscarinic ( $\mathrm{M})$ acetylcholine $\mathrm{M}_{3}$ and $\mathrm{M}_{5}$ receptors. Although numerous other neurotransmitter and receptor systems have roles in the vomiting reflex, the relationship among them are not yet clearly understood.

\section{Classification of CINV}

The classification of CINV is widely agreed upon within the antiemetic community. CINV is categorized into 3 groups: acute onset (mostly serotonin-related), occurring within the first $24 \mathrm{~h}$ of initiation of chemotherapy; delayed onset (in part substance P-related), occurring $24 \mathrm{~h}$ to several days after chemotherapy; and anticipatory, emesis that is triggered by external factors such as taste, odor or sight, as well as thoughts or anxiety due to poor response to antiemetic agents during a previous cycle of chemotherapy. 


\begin{tabular}{|c|c|c|}
\hline Antiemetic & Route & Recommended dose (once daily) \\
\hline \multicolumn{3}{|l|}{$5-\mathrm{HT}_{3-} \mathrm{RA}$} \\
\hline \multirow[t]{2}{*}{ Ondansetron } & p.o. & $8 \mathrm{mg}$ twice daily \\
\hline & $\begin{array}{l}\text { i.v. } \\
\text { p.o. }\end{array}$ & $\begin{array}{l}8 \mathrm{mg}(0.15 \mathrm{mg} / \mathrm{kg}) \\
2 \mathrm{mg}\end{array}$ \\
\hline Granisetron & i.v. & $1 \mathrm{mg}(0.01 \mathrm{mg} / \mathrm{kg})$ \\
\hline Tropisetron & $\begin{array}{l}\text { p.o. } \\
\text { i.v. }\end{array}$ & $5 \mathrm{mg}$ \\
\hline Palonosetron & $\begin{array}{l}\text { p.o. } \\
\text { i.v. }\end{array}$ & $\begin{array}{l}0.5 \mathrm{mg} \text { (only day } 1) \\
0.25 \mathrm{mg} \text { (only day } 1)\end{array}$ \\
\hline \multicolumn{3}{|l|}{ Steroids } \\
\hline Dexamethasone & p.o./i.v. & $\begin{array}{l}\text { Highly emetogenic: } 20 \mathrm{mg} \text {; if given with aprepitant } 12 \mathrm{mg} \\
\text { Moderately emetogenic: } 8 \mathrm{mg}\end{array}$ \\
\hline \multicolumn{3}{|l|}{$\mathrm{NK}_{1} \mathrm{RA}$} \\
\hline Aprepitant & p.o. & $125 \mathrm{mg}$ day $1,80 \mathrm{mg}$ day $2+3$ \\
\hline Fosaprepitant & i.v. & $150 \mathrm{mg}$ day 1 only \\
\hline
\end{tabular}

\section{Emetogenicity of Chemotherapeutic Agents}

The main risk factor linked to the development of CINV is the emetogenic potential of the administered chemotherapeutic agents. All international guidelines classify chemotherapeutic agents into 4 emetic risk groups according to their emetogenic potential: high $(90 \%)$, moderate $(30-90 \%)$, low (10$30 \%)$ and minimal $(<10 \%)$. The percentages represent the proportion of patients expected to have an emetic episode(s) if no prophylactic antiemetics were administered. The guideline committees continue to recognize the clinical utility of grouping chemotherapy agents into broad emetogenic categories to allow clinicians to adapt the antiemetic prophylaxis according to the emetogenicity of the chemotherapy. Table 1 highlights the emetogenic potential of chemotherapeutics most commonly administered as part of standard regimens for breast cancer.

\section{Patient-Related Risk Factors}

There are also patient-related factors that may contribute to the emetogenic risk of emesis. Risk factors known to increase the likelihood of CINV include young age, female gender, a history of low alcohol intake, motion sickness, experience of emesis during pregnancy, impaired quality of life, and previous exposure to chemotherapy. Despite these risk factors being well established, antiemetic guidelines have historically been based solely on the emetogenicity of the chemotherapy. However, when considering both the multiple patient-related risk factors inherent in many breast cancer patients and the wide range of the moderately emetogenic potential (30-90\%) of the chemotherapeutics used to treat breast cancer, integrating a patient-related risk factor profile into the guidelines may be warranted. However, further research would be needed, e.g. prospective validation studies, prior to implementation, and the feasibility of such a model in routine practice remains questionable [5]. In their most recent update, the ASCO guideline committee acknowledged that (young, female) cancer patients receiving AC-based chemotherapy represent a particularly challenging population. Consequently, they chose to re-classify AC chemotherapy from the previous category of moderately emetogenic to highly emetogenic, recognizing that the patient risk factors of those typically receiving AC were adding to the chemotherapy risk. Other guideline committees such as MASCC/European Society of Medical Oncology (ESMO) similarly acknowledged the higher risk of this group but retained the prior moderately emetogenic classification of AC.

\section{Antiemetics}

With a wide variety of modern antiemetic agents available for the prevention and treatment of CINV, vomiting can be prevented in the majority of patients [6]. However, nausea remains more difficult to control than vomiting, particularly in the delayed phase (days 2-5 after chemotherapy). As continued research strives to attain complete prevention of CINV for patients, nausea control should be a primary focus of future clinical trials.

As suggested by the antiemetic guidelines, combination antiemetic regimens targeting multiple molecular pathways have become the standard of care for the prevention of CINV.

\section{5-HT $\mathrm{T}_{3}$ Serotonin Receptor Antagonists}

Over the last 2 decades, antagonists inhibiting the actions of serotonin have been the most effective and most widely 
Table 3. Antiemetic prevention based on the emesis risk category; adapted from [1,2]

\begin{tabular}{llll}
\hline Emesis risk & Acute phase (day 1) & Followed by & Delayed phase (days 2-5) \\
\hline High & 5-HT 3 RA + DEX + aprepitant (or fosaprepitant) & $\rightarrow$ & $\begin{array}{l}\text { DEX (days 2-3 or 2-4) + aprepitant (days 2-3) } \\
\text { (if fosaprepitant used day 1, then DEX only) }\end{array}$ \\
$\begin{array}{ll}\text { AC-based } \\
\text { Moderate }\end{array}$ & $\begin{array}{l}\text { 5-HT } 3 \text { RA + DEX + aprepitant (or fosaprepitant) } \\
\text { palonosetron + DEX } \\
\text { (alternative 5-HT3 RA if palonosetron is not available) }\end{array}$ & $\rightarrow$ & DEX (days 2-3) \\
Low & DEX (or 5-HT RA or D RA) & $\rightarrow$ & None \\
Minimal & None & $\rightarrow$ & None
\end{tabular}

$\mathrm{AC}=$ anthracycline and cyclophosphamide, 5-HT $\mathrm{RA}=5-\mathrm{HT}_{3}$ receptor antagonist, $\mathrm{DEX}=$ dexamethasone, $\mathrm{D} \mathrm{RA}=$ dopamine receptor antagonist.

*In the American Society of Clinical Oncology (ASCO) guideline dexamethasone is also recommended in analogy to the high emetogenic risk group.

used antiemetics for the prophylaxis and management of CINV. Currently, 5 5- $\mathrm{HT}_{3}$ RAs are available: granisetron, ondansetron, palonosetron, ramosetron and tropisetron. When administering $5-\mathrm{HT}_{3} \mathrm{RAs}$, several points should be considered [2]:

- The lowest fully effective dose for each agent should be used; higher doses do not enhance any aspect of their activity because of receptor saturation.

- Oral and intravenous applications are equally effective.

- There is no more effective schedule than a single dose administered before chemotherapy.

The guideline-based dose recommendation is shown in table 2 .

While all of the 5- $\mathrm{HT}_{3}$ RAs form the cornerstone of therapy for the control of acute emesis caused by chemotherapy agents with moderate/high emetogenic potential, more recent data suggest that the newest $5-\mathrm{HT}_{3}$ RA, palonosetron, uniquely offers clinical benefit in also preventing delayed CINV [7]. This delayed benefit may be the result of pharmacologically distinct characteristics that palonosetron exhibits compared with the older 5- $\mathrm{HT}_{3}$ RAs. As the Phase III palonosetron trials in the setting of moderately emetogenic chemotherapy (MEC) suggested superiority over older 5-HT RAs, $_{3}$ the updated MASCC/ESMO and ASCO guidelines now recommend palonosetron as the preferred agent in patients receiving MEC $[1,2]$. The data and guideline recommendations are particularly relevant to a breast cancer population, as approximately half the patients in the Phase III palonosetron trials were females with breast cancer [7-9].

From to the broad experience acquired with $5-\mathrm{HT}_{3}$ RAs in clinical practice during that time, the remarkable safety profile of these drugs has been confirmed [10]. As a class, 5- $\mathrm{HT}_{3}$ RAs are well tolerated; common adverse events include mild headache, transient elevation of hepatic aminotransferase levels and constipation.

\section{$\mathrm{NK}_{1}$ Receptor Antagonists}

$\mathrm{NK}_{1}$ RAs exert their antiemetic action through the inhibition of substance $\mathrm{P}$ in both the central (mainly) and peripheral nervous systems. Aprepitant, approved as the first $\mathrm{NK}_{1}$ RA in 2003, and the follow-up intravenous (i.v.) formulation, fosaprepitant, are currently the only agents available in this class. Other $\mathrm{NK}_{1} \mathrm{RAs}$ such as netupitant and rolapitant are under investigation. Netupitant has been developed as a fixed-dose oral combination with palonosetron (NEPA), specifically designed to target 2 critical pathways involved in emesis with a single-dose product. In pivotal trials, NEPA has been shown to be superior to oral palonosetron in patients receiving highly emetogenic chemotherapy (HEC) [11] and in females with breast cancer receiving AC-based chemotherapy [12]. It has also been shown to be safe and highly effective over multiple cycles of MEC and HEC [13].

Aprepitant-containing regimens have been shown to significantly reduce acute and delayed emesis in patients receiving HEC $[6,14]$ and MEC $[15,16]$, compared with regimens containing $5-\mathrm{HT}_{3} \mathrm{RA}$ plus dexamethasone (DEX) only. It is therefore recommended for prophylactic use in combination with a $5-\mathrm{HT}_{3}$ RA plus DEX therapy during the acute phase. For delayed prevention, it is to be used alone on days 2-3 in AC MEC and in combination with DEX on days 2-3 in HEC (tables 2, 3).

Aprepitant is well tolerated, with headache, anorexia, fatigue, diarrhea, hiccups and mild transaminase elevation as the most common low-grade adverse effects reported during clinical trials [6, 14, 15]. Aprepitant is metabolized by cytochrome $\mathrm{P} 450$ (CYP) 3A4 and is a moderate inhibitor and an inducer of CYP3A4, as well as an inducer of CYP2C9. Therefore, potential interactions between aprepitant and other drugs, especially chemotherapeutics and other antiemetics have been investigated intensively [17]. The most notable findings are that aprepitant causes a 2-fold increase in the area under the plasma concentration curve (AUC) of DEX, a sensitive substrate of CYP3A4. Consequently, DEX doses should be decreased by approximately $50 \%$ when used in combination with aprepitant. After 10 years of clinical experience with aprepitant, the clinical relevance of these potential interactions appears to be rather insignificant [17]. Reassuringly, it has had no clinically significant effect on either the pharmacokinetics or toxicity of standard doses of docetaxel in cancer patients [18], and the metabolism of cyclophosphamide is not significantly reduced in the presence of aprepitant. 


\section{Corticosteroids}

Although not approved as antiemetics, corticosteroids are an integral component of most antiemetic regimens und play a major role in the prevention of both acute and delayed CINV [19, 20]. While no study has been performed to evaluate the antiemetic effectiveness of a particular corticosteroid versus another, dexamethasone remains the most frequently used. When used in combination with other antiemetics, corticosteroids exert an additive effect. Therefore, all guidelines suggest the use of DEX for the acute prevention in low emetogenic chemotherapy (LEC), MEC, and HEC settings, recommending a single dose of 4-8 $\mathrm{mg}$ in LEC, $8 \mathrm{mg}$ in MEC and $20 \mathrm{mg}$ in HEC (reduced to $12 \mathrm{mg}$ when administered with aprepitant due to the CYP3A4-dependent metabolism of DEX). For delayed prevention, DEX is recommended at a dose of $8 \mathrm{mg}$ twice a day for 3-4 days ( $8 \mathrm{mg}$ once daily when used with aprepitant or fosaprepitant) and in MEC at $8 \mathrm{mg}$ daily for 2-3 days. These dose recommendations are largely based on studies conducted by the Italian Group for Antiemetic Research [21].

Despite evidence of their beneficial effects, corticosteroids may be underutilized due to concerns regarding their potential side effects. In a study by Vardy et al. [22], patients receiving DEX for prevention of delayed CINV reported the following adverse events in the week following chemotherapy: moderate-to-severe insomnia (45\%), indigestion and/or epigastric discomfort $(27 \%)$, agitation (27\%), increased appetite $(19 \%)$, weight gain $(16 \%)$ and acne $(15 \%)$. As a result, there has been interest in minimizing the DEX dose and frequency, especially in patients who experience these DEX-related side effects. In addition, DEX should be used with caution in patients with pre-existing conditions that could be exacerbated by corticosteroid use (such as diabetes, cataracts, osteopenia/ osteoporosis). In a study of chemotherapy-naïve breast cancer patients, a single dose of palonosetron plus DEX on day 1 only showed complete response rates (no emesis, no rescue medication) similar to those of palonosetron on day 1 plus DEX on days 1-3 [23]. In the recent NEPA study in breast cancer patients receiving AC chemotherapy, the complete antiemetic regimen (NEPA plus DEX) was given on day 1 only [12]. The positive results validate the guideline recommendations of a single day of DEX in patients receiving $\mathrm{AC}$, and provide encouraging evidence that DEX beyond day 1 might be not necessary when using NEPA in patients at higher risk for CINV.

\section{Olanzapine}

Olanzapine is an atypical antipsychotic drug that displays antiemetic properties due to its impact on multiple receptor sites involved in the pathways controlling nausea and vomiting. In vitro and in vivo receptor binding studies showed that olanzapine exhibits a broad binding profile with high affinity for dopamine $\mathrm{D}_{1}-\mathrm{D}_{5}, 5-\mathrm{HT}_{2 \mathrm{~A}}, 5-\mathrm{HT}_{2 \mathrm{C}}, 5-\mathrm{HT}_{3}, 5-\mathrm{HT}_{6}$, muscarinic, alpha $\mathrm{a}_{1}$-adrenergic, and histamine $\mathrm{H}_{1}$ receptors.
There is no consistent recommendation has been given by the various guideline committees for appropriate utilization of olanzapine. It is recommended as an adjunctive drug for breakthrough CINV in the ASCO guidelines, with the general principle being to add an agent from a different drug class to the current regimen once breakthrough CINV has occurred [1]. This recommendation is supported by the study of Navari et al. [24] in which olanzapine was shown to be superior to metoclopramide when used in the rescue setting. Adverse effects reported for olanzapine are typical of those seen with other antipsychotic agents and include sleepiness, dizziness, weight gain and dry mouth.

\section{Dopamine Receptor Antagonists}

Before the introduction of 5-HT 3 RAs, dopamine-receptor antagonists formed the basis of antiemetic therapy [25]. Based on their chemical structure, these agents can be subdivided into phenothiazines, butyrophenones and substituted benzamides $[10,19]$. Prior to establishing the $5-\mathrm{HT}_{3}$ RAs in CINV prophylaxis, metoclopramide, 1 of the most frequently used benzamides, played a primary role in the management of acute CINV, usually given at high doses and in combination with a corticosteroid.

However, in patients receiving cisplatin-based chemotherapy, conventional high doses of metoclopramide are not significantly different from placebo. Consequently, metoclopramide is not recommended for the prevention of acute CINV by current guidelines. In addition, in 2013, in an effort to reduce the risk of neurological side effects, the European Medicines Agency recommended (1) removal of the high-strength formulation of metoclopramide from the market, (2) restriction of the maximum recommended dose, and (3) limited use to $\leq 5$ days.

Similar to the recommendations for olanzapine, ASCO guidelines recommend that metoclopramide be reserved for patients refractory to or intolerant of 5- $\mathrm{HT}_{3}$ RAs, DEX and aprepitant [1].

\section{Benzodiazepines}

As a valuable addition to antiemetic regimens, benzodiazepines may be used to treat certain conditions such as anxiety and to reduce the risk of anticipatory CINV. Benzodiazepines may also be effective in patients with refractory and breakthrough emesis [1].

\section{Ginger}

Ginger has long been known to exhibit efficacy in reducing nausea and is used in the treatment of hyperemesis gravidarum. Only recently it was shown that the antiemetic activity of ginger is based on the inhibition of human $5-\mathrm{HT}_{3}$ receptors. In a study (of predominantly females with breast cancer) comparing the effectiveness of ginger when given in combination with a $5-\mathrm{HT}_{3} \mathrm{RA}$, ginger was shown to significantly reduce acute nausea compared to placebo [26]. There- 
fore, an 'add on' ginger supplementation (500-1000 mg daily for 6 days, starting day -3) might be considered.

\section{Antiemetic Studies in Breast Cancer Patients}

As cisplatin is viewed as the most emetogenic chemotherapeutic agent, early antiemetic trials focused on this agent in assessing the efficacy of various agents. However, with growing interest in establishing good CINV control in the MEC setting, combined with growing awareness that women receiving $\mathrm{AC}$ or a similar combination are at a high risk of emesis, anthracycline-based chemotherapy has become the standard emetic stimulus in clinical trials assessing antiemetic agents among breast cancer patients. In fact, up to now AC has served as the predominant setting in which currently available 5-HT 3 RA and aprepitant MEC-approved indications have been based.

Some of the most recent and relevant large trials in breast cancer patients include: (1) the study of Saito et al. [7] demonstrating of superiority of palonosetron over granisetron in preventing delayed CINV in patients receiving MEC (43\% breast cancer patients receiving anthracycline-based chemotherapy); (2) the trial of Warr et al. [27] establishing superiority of the triplet aprepitant/ondansetron/ DEX regimen over a doublet ondansetron/DEX regimen in 857 breast cancer patients; (3) the follow-up study of Rapoport et al. [16] affirming the aprepitant triplet superiority over the $5-\mathrm{HT}_{3} \mathrm{RA} / \mathrm{DEX}$ doublet in 848 patients receiving MEC ( $50 \%$ of whom had breast cancer); and (4) the recent study by Aapro et al. [12] showing superiority of the new fixed- and single-dose NEPA/ DEX regimen over palonosetron/DEX in 1,449 patients $(97 \%$ breast cancer) receiving AC chemotherapy.

\section{Summary of Antiemetic Guideline Based Management of CINV}

\section{Highly Emetogenic Chemotherapy}

For acute CINV, a combination of a 5-HT 3 RA, DEX and aprepitant/fosaprepitant given prior to chemotherapy is recommended unanimously by all guidelines (table 3 ).

For delayed CINV, the necessity of appropriate prophylaxis for prevention of delayed CINV in HEC settings is based on studies showing that without any preventive agents, $60 \%$ to nearly $90 \%$ of patients receiving cisplatin will experience delayed emesis. All guidelines recommend a combination of DEX and aprepitant. If fosaprepitant is given on day 1 , no repetition of fosaprepitant on the consecutive days is necessary.

\section{AC-Based Chemotherapy}

It has to be noted that, while the ASCO guidelines consider AC regimens, commonly used in patients with breast cancer, as highly emetogenic, they remain classified as MEC regimens by the MASCC/ESMO guidelines. This discordance in the classification is simply due to differing approaches for recognizing that the patient-related risk factors contribute to the emetic risk for this population. Therefore, consistent with the HEC recommendations, the ASCO guidelines suggest delayed prophylaxis with both a $\mathrm{NK}_{1} \mathrm{RA}$ and $\mathrm{DEX}$, while the MASCC/ESMO guidelines limit their delayed recommendation exclusively to the use of aprepitant.

\section{Moderately Emetogenic Chemotherapy}

For acute CINV, patients should be given a combination of palonosetron and DEX. If palonosetron is unavailable, another $5-\mathrm{HT}_{3}$ RA can be substituted. The MASCC/ESMO guidelines limit their recommendation to this combination, whereas the ASCO guidelines suggest that the addition of aprepitant can be considered in selected patients. Although this is not clearly defined, the implication is that if clinicians feel that a patient presents at a higher risk (perhaps due to patient-related risk factors), the addition of the $\mathrm{NK}_{1}$ RA can be considered.

For delayed CINV, DEX alone is the preferred agent. However, if an aprepitant regimen was used for the prevention of acute CINV, aprepitant \pm DEX should be used. $5-\mathrm{HT}_{3}$ RAs may be used as an alternative agent to DEX, but not in the situation when palonosetron was the initial 5- $\mathrm{HT}_{3} \mathrm{RA}$ of choice.

\section{Low Emetogenic Chemotherapy}

The application of a single agent, e.g. a low dose of DEX, is sufficient for the prevention of both acute and delayed CINV. Although the routine use of 5- $\mathrm{HT}_{3}$ RAs has been observed in clinical practice, it is considered an over-treatment and should, therefore, be avoided in patients without additional risk factors.

\section{Minimally Emetogenic Chemotherapy}

All guideline suggest that most patients receiving minimally emetogenic chemotherapy do not require antiemetic prophylaxis and, therefore, nothing should be administered routinely.

\section{Management of Breakthrough and Refractory CINV}

'Breakthrough CINV' is defined as CINV that occurs despite optimal preventative treatment. 'Refractory CINV' is defined as the recurrence of CINV in subsequent cycles of chemotherapy when all previous preventive and rescue treatments failed. If the best possible treatment has already been given as prophylaxis, repeated dosing of the same agents is unlikely to be successful. In this setting, olanzapine may be the best option. Indeed, recent trials demonstrated its effectiveness in treating breakthrough CINV [28]. Further options are either the addition of dopamine receptor antagonists (e.g. metoclopramide) or other agents such as benzodiazepines or 
other neuroleptics. The use of cannabinoids can also be considered in patients with refractory CINV.

\section{Management of Radiation-Induced Nausea and Vomiting}

Since radiation therapy (RT) is part of the treatment plan of most breast cancer patients, the prevention and treatment of radiation-induced nausea and vomiting (RINV) also plays an important role in the overall care plan of these patients [29]. The recent guidelines from both MASCC/ESMO and ASCO divide the risk of emesis due to RT into 4 categories $[1,30]$. Most breast cancer patients receiving adjuvant radiation to the breast are at minimal risk of developing RINV, and, therefore, no prophylactic antiemetic treatment is necessary. Yet due to the generally elevated risk of nausea and emesis in young female patients, a rescue agent such as $5-\mathrm{HT}_{3}$ RAs or dopamine receptor antagonists may be used. In the low and moderate risk setting, prophylaxis with a $5-\mathrm{HT}_{3} \mathrm{RA}$ is recommended, possibly adjusted by adding DEX in the moderate risk setting. Although a high risk of developing RINV is not common in breast cancer treatment, prophylaxis with both 5-HT $\mathrm{HAs}_{3}$ and DEX is recommended for such patients. No randomized studies are available with regard to the potential value of an $\mathrm{NK}_{1} \mathrm{RA}$ in this setting.

\section{Conclusion}

While the introduction of the 5- $\mathrm{HT}_{3}$ RA class transformed CINV prevention for patients 20 years ago, the pathophysiology of CINV itself has been elucidated during the last decade of research. Antiemetic combinations targeting multiple molecular pathways have been identified, and the $\mathrm{NK}_{1}$ RA class has been introduced into the antiemetic armamentarium, essentially optimizing CINV control for the majority of patients. However, this control can only be achieved if appropriate antiemetic prophylaxis is administered to patients. Despite some differences between the guidelines, they all provide reliable, up-to-date and reasonably consistent recommendations to guide clinicians on the ideal use of antiemetics. Unfortunately, adherence to antiemetic guidelines is suboptimal, despite research suggesting that guideline conformity improves CINV control [31]. In a large observational study performed recently in nearly 1000 patients in 8 European countries, Aapro and colleagues [31] showed guideline adherence in only $29 \%$ of patients. They also showed better CINV control and less utilization of health care resources in those patients receiving guideline-consistent CINV prophylaxis. Clearly, a need exists for greater adherence to the guideline recommendations to improve the quality of care for cancer patients. While studies are needed to identify specific barriers to guideline use within individual clinics and hospitals, measures that can be taken to enhance adherence include efficient education, monitoring and training of all staff, use of standardized antiemetic protocols included in chemotherapy order forms, providing feedback to clinicians on patient CINV outcomes and clinical interventions by pharmacists in the event of insufficient antiemetic orders.

As females with breast cancer represent a particularly challenging population in terms of emesis control, it is especially crucial that antiemetic recommendations are followed to allow these patients to maintain their quality of life and continue their cancer treatment plan. Further research is warranted to explore the underlying pathophysiology of nausea so that new treatments can be developed to optimize nausea prevention, to evaluate opportunities to reinforce and encourage guideline implementation in clinical practice, and to see if novel guideline-based antiemetic combinations (such as netupitant/palonosetron) will improve CINV control for patients.

\section{Acknowledgement}

The authors would like to thank Jennifer Vanden Burgt for the independent editorial assistance during final stages of development of this manuscript.

\section{Disclosure Statement}

The authors hold no shares in any drug company. K. Jordan has received study grants, honoraria for consultancy and/or is on the speaker bureau of MSD, Merck, Helsinn, and Pro-Strakan. F. Jahn She has received honoraria of MSD, Helsinn and Roche. C. Müller-Tidow has received study grants, honoraria for consultancy and/or is on the speaker bureau of Amgen, Janssen Cilag, Novartis, Celgene and Roche. B. Jordan has received honoraria for consultancy and/or is on the speaker bureau of Temmler and Teva.

\section{References}

1 Basch E, Prestrud AA, Hesketh PJ, et al.: American Society of Clinical Oncology Clinical Practice Guideline update. J Clin Oncol 2011;29:4189-4198.

2 Roila F, Herrstedt J, Aapro M, et al.: Guideline update for MASCC and ESMO in the prevention of chemotherapy- and radiotherapy-induced nausea and vomiting: Results of the Perugia consensus conference. Ann Oncol 2010;21 Suppl 5:v232-243.
3 Carpenter DO, Briggs DB, Strominger N: Responses of neurons of canine area postrema to neurotransmitters and peptides. Cell Mol Neurobiol 1983;3:113-126.

4 Darmani NA, Ray AP: Evidence for a re-evaluation of the neurochemical and anatomical bases of chemotherapy-induced vomiting. Chem Rev 2009; 109:3158-3199.
5 Jordan K, Gralla R, Jahn F, Molassiotis A: International antiemetic guidelines on chemotherapy induced nausea and vomiting (CINV): Content and implementation in daily routine practice. Eur J Pharmacol 2014;722:197-202. 
6 Hesketh PJ, Grunberg SM, Gralla RJ, et al.: The oral neurokinin-1 antagonist aprepitant for the prevention of chemotherapy-induced nausea and vomiting: A multinational, randomized, double-blind, placebo-controlled trial in patients receiving highdose cisplatin--the Aprepitant Protocol 052 Study Group. J Clin Oncol 2003;21:4112-4119.

7 Saito M, Aogi K, Sekine I, et al.: Palonosetron plus dexamethasone versus granisetron plus dexamethasone for prevention of nausea and vomiting during chemotherapy: A double-blind, double-dummy, randomised, comparative phase III trial. Lancet Oncol 2009;10:115-124.

8 Eisenberg P, Figueroa-Vadillo J, Zamora R, et al: Improved prevention of moderately emetogenic chemotherapy-induced nausea and vomiting with palonosetron, a pharmacologically novel 5-HT3 receptor antagonist: Results of a phase III, singledose trial versus dolasetron. Cancer 2003;98:24732482.

9 Gralla R, Lichinitser M, Van Der Vegt S, et al.: Palonosetron improves prevention of chemotherapyinduced nausea and vomiting following moderately emetogenic chemotherapy: Results of a doubleblind randomized phase III trial comparing single doses of palonosetron with ondansetron. Ann Oncol 2003;14:1570-1577.

10 Hesketh PJ: Chemotherapy-induced nausea and vomiting. N Engl J Med 2008;358:2482-2494.

11 Hesketh PJ, Rossi G, Rizzi G, et al.: Efficacy and safety of NEPA, an oral combination of netupitant and palonosetron, for prevention of chemotherapyinduced nausea and vomiting following highly emetogenic chemotherapy: A randomized dose-ranging pivotal study. Ann Oncol 2014;25:1340-1346.

12 Aapro M, Rugo H, Rossi G, et al.: A randomized phase III study evaluating the efficacy and safety of NEPA, a fixed-dose combination of netupitant and palonosetron, for prevention of chemotherapy-induced nausea and vomiting following moderately emetogenic chemotherapy. Ann Oncol 2014;25: $1328-1333$.
13 Gralla RJ, Bosnjak SM, Hontsa A, et al.: A phase III study evaluating the safety and efficacy of NEPA, a fixed-dose combination of netupitant and palonosetron, for prevention of chemotherapy-induced nausea and vomiting over repeated cycles of chemotherapy. Ann Oncol 2014;25:1333-1339.

14 Schmoll HJ, Aapro MS, Poli-Bigelli S, et al.: Comparison of an aprepitant regimen with a multipleday ondansetron regimen, both with dexamethasone, for antiemetic efficacy in high-dose cisplatin treatment. Ann Oncol 2006;17:1000-1006.

15 Warr D, Grunberg, SM, Gralla, RJ, et al.: The oral $\mathrm{NK}(1)$ antagonist aprepitant for the prevention of acute and delayed chemotherapy-induced nausea and vomiting: Pooled data from 2 randomised, double-blind, placebo controlled trials. Eur J Cancer 2005;41:1278-1285.

16 Rapoport BL, Jordan K, Boice JA, et al.: Aprepitant for the prevention of chemotherapy-induced nausea and vomiting associated with a broad range of moderately emetogenic chemotherapies and tumor types: A randomized, double-blind study. Support Care Cancer 2010;18:423-431.

17 Aapro MS, Walko CM: Aprepitant: Drug-drug interactions in perspective. Ann Oncol 2010;21:23162323.

18 Nygren P, Hande K, Petty KJ, et al.: Lack of effect of aprepitant on the pharmacokinetics of docetaxel in cancer patients. Cancer Chemother Pharmacol 2005;55:609-616.

19 Jordan K, Schmoll HJ, Aapro MS: Comparative activity of antiemetic drugs. Crit Rev Oncol Hematol 2007:61:162-175.

20 Grunberg SM: Antiemetic activity of corticosteroids in patients receiving cancer chemotherapy: Dosing, efficacy, and tolerability analysis. Ann Oncol 2007;18:233-240.

21 Italian Group for Antiemetic Research: Randomized, double-blind, dose-finding study of dexamethasone in preventing acute emesis induced by anthracyclines, carboplatin, or cyclophosphamide. J Clin Oncol 2004;22:725-729.

22 Vardy J, Chiew KS, Galica J, et al.: Side effects associated with the use of dexamethasone for prophylaxis of delayed emesis after moderately emetogenic chemotherapy. Br J Cancer 2006;94:10111015 .
23 Aapro M, Fabi A, Nole F, et al.: Double-blind, randomised, controlled study of the efficacy and toler ability of palonosetron plus dexamethasone for 1 day with or without dexamethasone on days 2 and 3 in the prevention of nausea and vomiting induced by moderately emetogenic chemotherapy. Ann Oncol 2010;21:1083-1088.

24 Navari RM, Nagy CK, Gray SE: The use of olanzapine versus metoclopramide for the treatment of breakthrough chemotherapy-induced nausea and vomiting in patients receiving highly emetogenic chemotherapy. Support Care Cancer 2013;21:16551663.

25 Feyer P, Jordan K: Update and new trends in antiemetic therapy: The continuing need for novel therapies. Ann Oncol 2011;22:30-38.

26 Ryan JL, Heckler CE, Roscoe JA, et al.: Ginger (Zingiber officinale) reduces acute chemotherapyinduced nausea: A URCC CCOP study of 576 patients. Support Care Cancer 2012;20:1479-1489.

27 Warr DG, Hesketh PJ, Gralla RJ, et al.: Efficacy and tolerability of aprepitant for the prevention of chemotherapy-induced nausea and vomiting in patients with breast cancer after moderately emetogenic chemotherapy. J Clin Oncol 2005;23:28222830.

28 Navari RM: Olanzapine for the prevention and treatment of chronic nausea and chemotherapyinduced nausea and vomiting. Eur J Pharmacol 2014;722:180-186.

29 Feyer P, Jahn F, Jordan K: Radiation induced nausea and vomiting. Eur J Pharmacol 2014;722: 165-171.

30 Feyer PC, Maranzano E, Molassiotis A, et al.: Radiotherapy-induced nausea and vomiting (RINV): MASCC/ESMO guideline for antiemetics in radiotherapy: Update 2009. Support Care Cancer 2011;19 Suppl 1:S5-14.

31 Aapro M, Molassiotis A, Dicato M, et al.: The effect of guideline-consistent antiemetic therapy on chemotherapy-induced nausea and vomiting (CINV): The Pan European Emesis Registry (PEER). Ann Oncol 2012;23:1986-1992. 